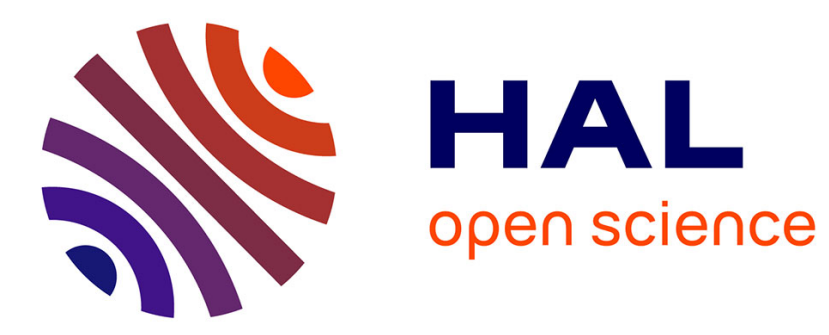

\title{
Towards an enhanced coupling between the Er ions and Si nanoclusters
}

\author{
L. Khomenkova, F. Gourbilleau, J. Cardin, R. Rizk
}

\section{To cite this version:}

L. Khomenkova, F. Gourbilleau, J. Cardin, R. Rizk. Towards an enhanced coupling between the Er ions and Si nanoclusters. Physica E: Low-dimensional Systems and Nanostructures, 2009, 41 (6), pp.1048-1051. 10.1016/j.physe.2008.08.016 . hal-01622760

\section{HAL Id: hal-01622760 \\ https://hal.science/hal-01622760}

Submitted on 24 Oct 2017

HAL is a multi-disciplinary open access archive for the deposit and dissemination of scientific research documents, whether they are published or not. The documents may come from teaching and research institutions in France or abroad, or from public or private research centers.
L'archive ouverte pluridisciplinaire HAL, est destinée au dépôt et à la diffusion de documents scientifiques de niveau recherche, publiés ou non, émanant des établissements d'enseignement et de recherche français ou étrangers, des laboratoires publics ou privés. 


\title{
Towards an enhanced coupling between the Er ions and Si nanoclusters
}

\author{
L. Khomenkova*, F. Gourbilleau, J. Cardin, R. Rizk \\ CIMAP, UMR CNRS/CEA/ENSICAEN/ Université de Caen, 6 Bd Maréchal Juin, 14050 Caen Cedex 4, France
}

\begin{abstract}
A B S T R A C T
The reactive magnetron co-sputtering of two confocal $\mathrm{SiO}_{2}$ and $\mathrm{Er}_{2} \mathrm{O}_{3}$ cathodes in argon-hydrogen plasma was used to deposit Er-doped Si-rich-SiO ${ }_{2}$ layers. The effects of deposition conditions (such as hydrogen rate and substrate temperature) and annealing treatment (temperature and time) on the structural, compositional and photoluminescence (PL) properties of the layers were examined. An enhancement was observed of both $\mathrm{Er}^{3+} \mathrm{PL}$ emission and $\mathrm{Er}^{3+}$ lifetime at $1.54 \mu \mathrm{m}$ in comparison with their counterparts for the best samples reported so far. It was shown that a lifetime as high as $9 \mathrm{~ms}$ can be reached, with comparable PL intensities for resonant and non-resonant excitation lines. The effective cross-section and the fraction of Er ions coupled to Si clusters are analyzed.
\end{abstract}

Keywords:

Reactive magnetron sputtering

Si nanocluster

Erbium

Photoluminescence

Lifetime

\section{Introduction}

Erbium-doped materials are under an intense research because of their potential optoelectronic and photonic applications due to sharp photoluminescence (PL) at $1.54 \mu \mathrm{m}$. Such emission comes from the ${ }^{4} \mathrm{I}_{13 / 2}-{ }^{4} \mathrm{I}_{15 / 2}$ transition in the internal $4 \mathrm{f}$-shell of the $\mathrm{Er}^{3+}$ ions and corresponds to the minimum absorption of the silicabased optical fibres.

During the last years, numerous Si-based materials have been investigated as a host for Er ions, like crystalline silicon (c-Si) and sub-stoichiometric $\mathrm{SiO}_{x}(1<x<2)$ up to $\mathrm{SiO}_{2}$ [1]. In c-Si, a strong temperature quenching of the $\mathrm{Er}^{3+} \mathrm{PL}$ was observed and attributed to Auger de-excitation and energy back-transfer processes [2], while in Er-doped- $\mathrm{SiO}_{2}$ materials the de-excitation processes of the $\mathrm{Er}^{3+} \mathrm{PL}$ are practically absent but suffers from the low excitation cross-section of $\mathrm{Er}, \sigma_{\text {eff }}\left(\sim 10^{-21} \mathrm{~cm}^{2}\right)$ [3] that requests pumping by expensive high-power lasers.

However, the sub-stoichiometric $\mathrm{SiO}_{x}$ or Si-rich silicon oxide (SRSO) appears highly interesting as host material, since it leads to nearly two orders of magnitude enhancement of the $\mathrm{Er}^{3+} \mathrm{PL}$, compared to Er-doped $\mathrm{SiO}_{2}$ [4-9]. This effect was attributed to the presence of $\mathrm{Si}$ nanoclusters, Si-nc, and to a strong coupling between them and $\mathrm{Er}^{3+}$ ions [5-10]. Then the increase of $\sigma_{\text {eff }}$ up to $10^{-16} \mathrm{~cm}^{-2}$ [11] was demonstrated, corresponding to the absorption cross-section of Si-nc [12]. The sensitizing role is independent of the crystalline or amorphous nature of Si-nc $[13,14]$, and the

\footnotetext{
* Corresponding author. Tel.: +33 231452656; fax: +33 231452660 .
}

E-mail address: larysa.khomenkova@ensicaen.fr (L. Khomenkova). energy transfer from Si-nc to $\mathrm{Er}^{3+}$ ions is highly dependent on their separating distance, which should be less than $0.5 \mathrm{~nm}$ $[15,16]$. Such a distance dependence is considered to be responsible for the few percentage of Er coupled to Si-nc $[8,17]$.

Recently, our team has developed a novel approach for the fabrication of Er-SRSO layers by the reactive co-sputtering of two confocal cathodes of $\mathrm{Er}_{2} \mathrm{O}_{3}$ and $\mathrm{SiO}_{2}$, instead of the reactive sputtering of a single $\mathrm{SiO}_{2}$ target topped by $\mathrm{Er}_{2} \mathrm{O}_{3}$ chips, as described in Refs. [14,16-18]. Moreover, the deposition was made on a rotating substrate, leading to a better homogeneity of both growth and composition of the layers. The content of $\mathrm{Er}$ and $\mathrm{Si}$ excess can be finely and independently tuned through the monitoring of the RF power applied on each cathode, the hydrogen rate $r_{\mathrm{H}}$ and the substrate temperature $T_{\mathrm{S}}$.

\section{Experimental}

The layers investigated have been fabricated by the reactive magnetron co-sputtering of 2 in confocal pure $\mathrm{SiO}_{2}$ and $\mathrm{Er}_{2} \mathrm{O}_{3}$ cathodes under argon-hydrogen mixture onto 4 in silicon p-type substrates. The incorporation of Si excess in the layers was due to the ability of hydrogen to reduce reactively the oxygen species present in plasma, as previously described in Ref. [19]. The control of the $\mathrm{Si}$ excess in the layers was made through the variation of the hydrogen rate $r_{\mathrm{H}}=F_{\mathrm{H}_{2}} /\left(F_{\mathrm{H}_{2}}+F_{\mathrm{Ar}}\right)$, where $F_{\mathrm{H}_{2}}$ and $F_{\mathrm{Ar}}$ are the values of gas flow for hydrogen and argon, respectively. The total flow of both gases was kept constant at $10 \mathrm{sccm}$, while the variation of $F_{\mathrm{H}_{2}}$ from 2 to $8 \mathrm{sccm}$ allows modifying the $r_{\mathrm{H}}$ value in 
the range $20-80 \%$. The total pressure in the chamber and the power density applied onto $\mathrm{SiO}_{2}$ and $\mathrm{Er}_{2} \mathrm{O}_{3}$ cathodes were fixed at 3 mTorr, 7.4 and $0.74 \mathrm{~W} / \mathrm{cm}^{2}$, respectively, while the substrate temperature $\left(T_{\mathrm{S}}\right)$ was varied between 50 and $200^{\circ} \mathrm{C}$. All the layers were annealed at $700-900^{\circ} \mathrm{C}$ during $2-60 \mathrm{~min}$ in nitrogen flow.

The Si excess and disorder in the layers were studied by means of the Fourier transform infra red (FTIR) absorption technique. FTIR spectra were recorded under normal and Brewster incident angle $\left(65^{\circ}\right)$ in the range $500-4000 \mathrm{~cm}^{-1}$ using a Nicolet Nexus spectrometer.

Energy-dispersive spectroscopy (EDS) was performed to check the composition of the layers, allowing the estimate of the $\mathrm{Er}$ content to about (3-4) $\times 10^{20} \mathrm{~cm}^{-3}$ for all layers investigated. The thickness and the refractive index of the layers were determined by spectroscopic ellipsometry and/or m-lines methods.

PL spectra of SRSO-Er layers were detected at room temperature using a Jobin Yvon $1 \mathrm{~m}$ single grating monochromator and Northcoast germanium detector cooled with liquid nitrogen. PL was excited by means of $\mathrm{Ar}^{+}$-laser operating at either $476 \mathrm{~nm}$ (non-resonant) or $488 \mathrm{~nm}$ (resonant) lines. The pumping photon flux was varied in the range $1 \times 10^{16}-4 \times 10^{20} \mathrm{ph} / \mathrm{cm}^{2} \mathrm{~s}$. For the sake of comparison, all the PL spectra were normalized on the excited volume after being recorded with a photon flux of $4 \times 10^{18} \mathrm{ph} / \mathrm{cm}^{2} \mathrm{~s}$ for both excitations. The lifetime study was performed with a flux of $1 \times 10^{16} \mathrm{ph} / \mathrm{cm}^{2} \mathrm{~s}$.

\section{Results and discussion}

The variation of the processing conditions (growth and thermal treatment) was performed with the aim of optimizing the Er PL and an enhancement of the fraction of coupled $\mathrm{Er}^{3+}$ ions.

\subsection{Effect of hydrogen rate}

The typical effect of $r_{\mathrm{H}}$ on the PL properties of SRSO-Er is demonstrated for the layer deposited at $T_{\mathrm{S}}=100{ }^{\circ} \mathrm{C}$ and annealed at $900{ }^{\circ} \mathrm{C}$ during $60 \mathrm{~min}$ (Fig. 1, curve 1 ). The PL intensity improves with the first stages of $r_{\mathrm{H}}$ increase, reaches a maximum for $r_{\mathrm{H}} \sim 55 \%$, before decreasing when $r_{\mathrm{H}}$ is further increased up to $80 \%$. This contrasts with the observed continuing decrease of $\mathrm{Er}^{3+}$ lifetime (Fig. 1, curve 2). Such behaviours of PL parameters could be explained by the variation of excess $\mathrm{Si}$, as well as by the change of the proportion of coupled Er.

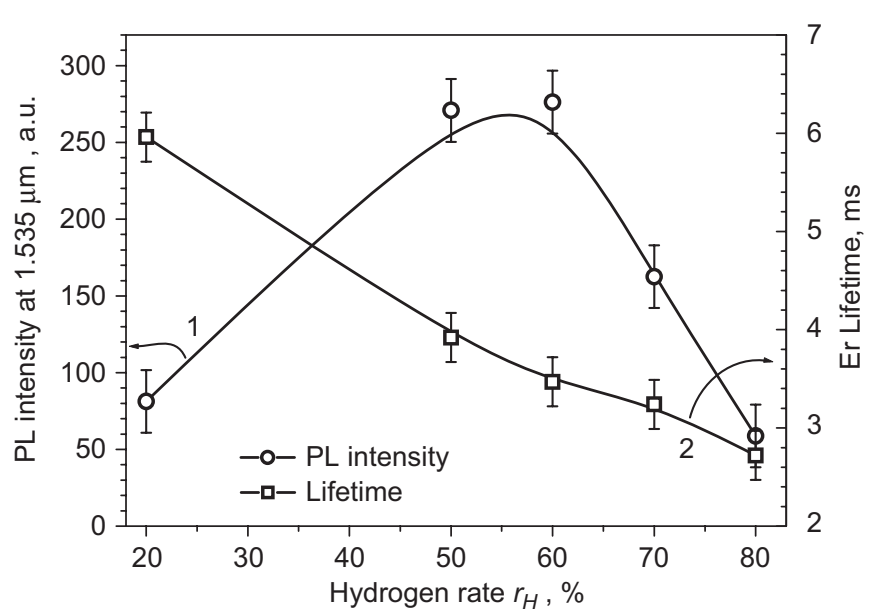

Fig. 1. Dependence of $\mathrm{Er}^{3+} \mathrm{PL}$ intensity (curve 1) and lifetime (curve 2) of SRSO-Er layers deposited at $T_{\mathrm{S}}=100{ }^{\circ} \mathrm{C}$ on the hydrogen rate $r_{\mathrm{H}}$. The measurements were made by using the non-resonant excitation line $(476 \mathrm{~nm})$.
The Si excess induced by $r_{\mathrm{H}}$ variation was estimated from the evolution of the FTIR spectra recorded at normal incidence (not shown) following the method described in Ref. [20]. Briefly summarized, this method is based on a linear relation between the shift on the $\mathrm{TO}_{3}$ peak position for a sub-stoichiometric $\mathrm{SiO}_{x}$ $(1<x<2)$ matrix, with respect to that of $\mathrm{SiO}_{2}$, and the stoichiometric coefficient $x$. The highest Si excess was found around 10 at\%, while the Si excess for the layers showing the highest PL has been estimated to be about 5 at\%. These results were also confirmed by EDS measurements. The increase in the excess $\mathrm{Si}$ is expected to enhance the density and/or the average size of Si-nc, which are still amorphous and then hardly observable by transmission electron microscopy [21].

Consequently, the increase in the PL intensity, when $r_{\mathrm{H}}$ is increased from $20 \%$ to $55 \%$, could be explained by the increasing density of Si-nc sensitizers, which, in turn, improves the fraction of coupled Er. However, for higher values of $r_{\mathrm{H}}\left(r_{\mathrm{H}}>55 \%\right)$ that induce more and more $\mathrm{Si}$ excess, one expects some increase in the average size of Si-nc at the expense of their density and their coupling with $\mathrm{Er}$ ions. This might explain the observed PL decrease for $r_{\mathrm{H}}>55 \%$, even though the concomitant increasing disorder can also contribute to such a behaviour. The increase of the disorder with the Si excess is confirmed by the evolution of the $\mathrm{TO}_{4}-\mathrm{LO}_{4}$ doublet of the FTIR spectra recorded at Brewster incidence (not shown), and is considered responsible for the gradual decrease of the $\mathrm{Er}^{3+}$ lifetime shown in Fig. 1. It is worth noting that the highest PL intensity for this series corresponds to a lifetime of 3.5-4 ms.

\subsection{Effect of the temperature of substrate}

The analysis of the effect of $T_{\mathrm{S}}$ on the $\mathrm{Er}^{3+} \mathrm{PL}$ properties of SRSO-Er layers is presented for the samples showing the best PL features in the previous section $\left(r_{\mathrm{H}}\right.$ effect). Fig. 2 shows the evolution of both $\mathrm{Er}^{3+} \mathrm{PL}$ and lifetime against $T_{\mathrm{S}}$ for the layers deposited at $r_{\mathrm{H}}=60 \%$ and then annealed at $900{ }^{\circ} \mathrm{C}$ during $60 \mathrm{~min}$. Both PL intensity and lifetime demonstrate behaviours similar to their counterparts for the $r_{\mathrm{H}}$ effect (Fig. 1). After a first increase, the PL reaches a maximum for $T_{\mathrm{S}}=80-100^{\circ} \mathrm{C}$, before decreasing for higher values of $T_{\mathrm{S}}$. In contrast, the lifetime shows a smooth continuous decrease from 4.5 to $3.0 \mathrm{~ms}$, when $T_{\mathrm{S}}$ is increased from 50 to $200{ }^{\circ} \mathrm{C}$.

Although $r_{\mathrm{H}}$ was maintained constant at $60 \%$, the increase of $T_{\mathrm{S}}$ favours the incorporation of $\mathrm{Si}$. Thus, when $T_{\mathrm{S}}$ is increased

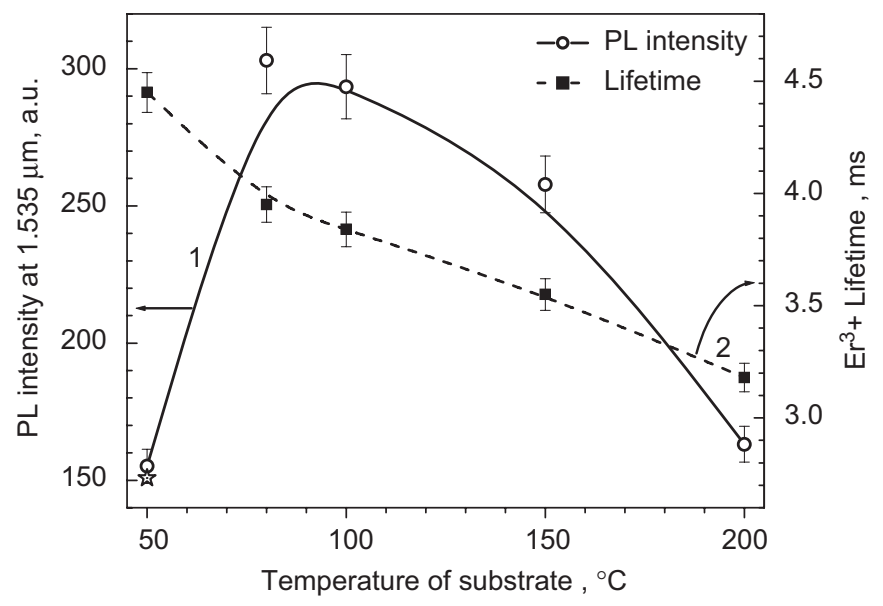

Fig. 2. Evolutions of the $\mathrm{Er}^{3+} \mathrm{PL}$ intensity (curve 1 ) and lifetime (curve 2) recorded with the non-resonant excitation wavelength $(476 \mathrm{~nm})$ on the layers grown with $r_{\mathrm{H}}=60 \%$, as a function of the substrate temperature $T_{\mathrm{S}}$. The intensity of the reference sample is indicated by a star symbol. 
from 100 to $200{ }^{\circ} \mathrm{C}$, the Si excess was increased from 5 to 8 at\%, while the Er content appears unaffected $\left(3.5-3.8 \times 10^{20} \mathrm{~cm}^{-3}\right)$. As already commented for the $r_{\mathrm{H}}$ effects, the smooth decrease of the lifetime is due to the $T_{\mathrm{S}}$-induced smooth increase of $\mathrm{Si}$ excess. Note that our layers are still showing PL higher than the 'standard' sample described in Ref. [18], whose PL intensity is marked by a star symbol in Fig. 2.

\subsection{Effect of annealing treatment}

No $\mathrm{Er}^{3+}$ emission was observed from the as-deposited layers, while short ( $2 \mathrm{~min}$ ) annealing at $800^{\circ} \mathrm{C}$ results in the appearance of notable $\mathrm{Er}^{3+}$ emission (Fig. 3a). The increase of the annealing time from 2 to $60 \mathrm{~min}$ has led to double the PL intensity, while the lifetime increases from about $2.1 \mathrm{~ms}$ to nearly $5 \mathrm{~ms}$. To mention that the annealing at the same temperature of the layers described in the previous sections leads to the following behaviours (data not shown): (i) the lifetime shows a higher value (about $3.5 \mathrm{~ms}$ ) after $2 \mathrm{~min}$ annealing and increases steeply to a saturation value as high as $8.8 \mathrm{~ms}$ for $30 \mathrm{~min}$ treatment and (ii) the PL intensity reaches a maximum after 30 min annealing and then decreases slightly for longer treatment.

The structural changes induced by the thermal treatment have been analyzed through the evolution of the FTIR spectra. The

a

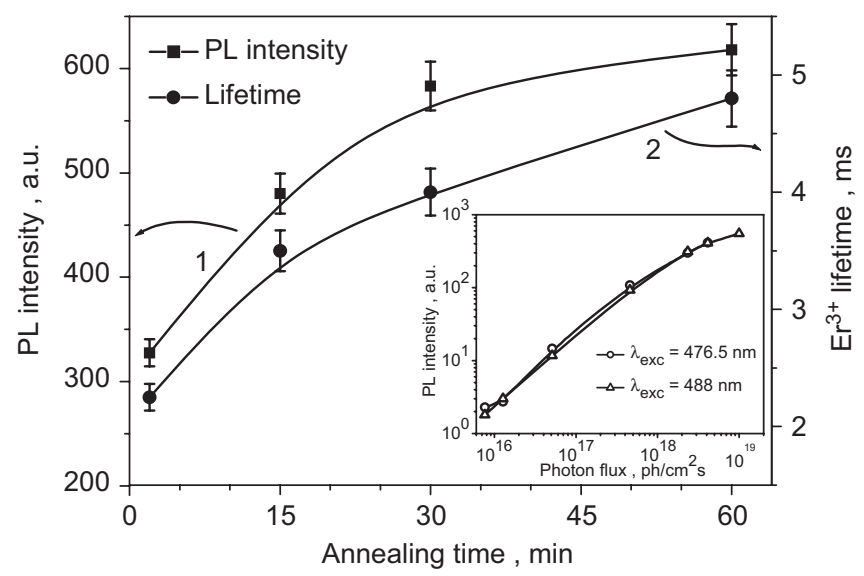

b

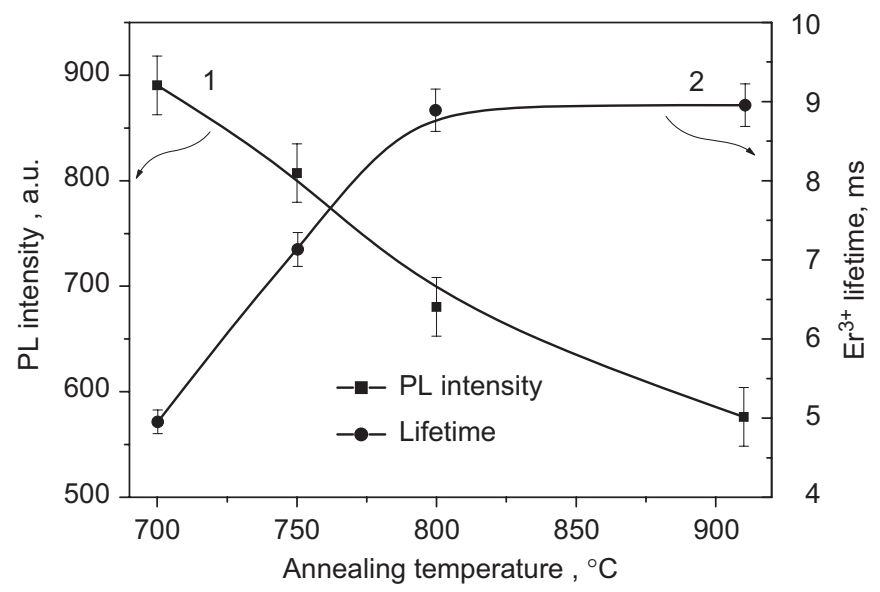

Fig. 3. (a) Variations of the $\mathrm{Er}^{3+} \mathrm{PL}$ intensity (curve 1) and lifetime (curve 2) with the annealing duration. $T_{\mathrm{a}}=800^{\circ} \mathrm{C}$. The inset compares the evolutions of the PL intensity against the photon flux for the two indicated excitation wavelengths, and for the layer annealed during $15 \mathrm{~min}$. (b) Variations of the $\mathrm{Er}^{3+} \mathrm{PL}$ intensity (curve 1) and lifetime (curve 2) towards the annealing temperature, using the same excitation conditions of (a) for the sample annealed during $60 \mathrm{~min}$. short-time annealing leads to a sharp shift of $\mathrm{TO}_{3}$ and $\mathrm{LO}_{3}$ vibration bands towards the high-frequency side, indicating the occurrence of phase separation in the layers. Longer annealing resulted mainly in the increase of the intensity of the $\mathrm{LO}_{3}$ band and the decrease of the $\mathrm{TO}_{4}-\mathrm{LO}_{4}$ doublet, suggesting an increase of the $\mathrm{Si} / \mathrm{SiO}_{2}$ interface area and an improvement of the oxide matrix, respectively.

The evolution of either the $\mathrm{Er}^{3+} \mathrm{PL}$ intensity and lifetime with the annealing temperature $T_{\mathrm{a}}$ is displayed in Fig. 3b. This figure shows a gradual decrease of the PL intensity vs. $T_{\mathrm{a}}$, while the lifetime increases rapidly to a saturation value of about $9 \mathrm{~ms}$ when $T_{\mathrm{a}}$ is increased to $800^{\circ} \mathrm{C}$.

\subsection{Analysis of the PL properties of the layer fabricated at optimal conditions}

In this section, we will comment on the results obtained for the layers with the highest PL intensity that exceeds four times the one for the best "standard" layers described in Ref. [18]. Note that the present layers contain less Si excess (5at\% vs. 7 at\%) and similar Er content $\left(\sim 3.5 \times 10^{20} \mathrm{at} / \mathrm{cm}^{3}\right)$. So, such efficiency could originate from the higher coupling rate between $\mathrm{Si}$-nc and $\mathrm{Er}^{3+}$ ions.

The dependence of $\mathrm{Er}^{3+} \mathrm{PL}$ intensity on photon flux was measured under non-resonant $(476 \mathrm{~nm})$ and resonant $(488 \mathrm{~nm})$ excitation to examine the coupling between $\mathrm{Er}^{3+}$ ions and $\mathrm{Si}$ clusters. From the inset of Fig. 3a, one can notice that the $\mathrm{Er}^{3+}$ emissions measured under the two excitation lines are comparable, while one expects higher Er PL under resonant excitation owing to the contribution of all optically active $\mathrm{Er}^{3+}$ ions (coupled and non-coupled to Si-nc).

We take into account that the $\mathrm{Er}^{3+} \mathrm{PL}$ intensity at non-resonant excitation is proportional to $I_{\mathrm{PL}}^{\mathrm{Er}} \sim \sigma_{\text {eff }} \tau_{\text {decay }} N_{\mathrm{Er}}^{*} \Phi / \tau_{\text {rad }}$, where $\sigma_{\text {eff }}$ is the effective absorption cross-section, $\tau_{\text {decay }}$ is the measured lifetime, $N^{*}$ Er is the number of $\mathrm{Er}^{3+}$ ions coupled to $\mathrm{Si}-\mathrm{nc}, \Phi$ is the photon flux and $\tau_{\text {rad }}$ is the radiative lifetime. The $\tau_{\text {decay }}$ is $\sim 6.3 \mathrm{~ms}$ for the layers investigated against 5 ms observed in Ref. [18], while the effective absorption cross-section, $\sigma_{\text {eff, was found to be the }}$ same $\left(4 \times 10^{-17} \mathrm{~cm}^{-2}\right)$. The increase of $\tau_{\text {decay }}$ only could not explain the increase of PL intensity four times in the present layers. And hence we can assume that there is an increase of the fraction of $\mathrm{Er}$ ions coupled to $\mathrm{Si}-\mathrm{nc}$. The comparison of the PL intensities showed that the latter is about $11 \%$ of the total $\mathrm{Er}$ concentration instead of 3\% reported for the former samples [18]. It is worth noting that such increase of the fraction of $\mathrm{Er}^{3+}$ ions coupled to Si-nc was also confirmed following the appropriate procedures described in Ref. [18]. However, in spite of promising results obtained in the present study, further improvement is needed to achieve a net gain in such layers.

\section{Conclusions}

In this paper, we have shown that the reactive co-sputtering of confocal targets allows the fabrication of SRSO-Er layers that show a significant enhancement of both $\mathrm{Er}^{3+} \mathrm{PL}$ emission and $\mathrm{Er}^{3+}$ lifetime at $1.54 \mu \mathrm{m}$, in comparison with their counterparts for the best samples reported so far. The monitoring of the deposition and annealing conditions have enabled notable progress in the optimization of the material, leading to the increase of the fraction of coupled Er from a few \% to about $11 \%$ with a lifetime reaching 8-9 ms. The observation of comparable $\mathrm{Er}^{3+} \mathrm{PL}$ intensities under resonant and non-resonant excitations is indicative of the efficient sensitizing role of Si-nc towards the coupled Er ions, while the high lifetime would reflect the quality of both host matrix and surrounding of the Er ions. Finally, in spite of the 
promising results, further improvements are necessary to obtain a net gain in the Er-coupled Si nanocluster material.

\section{Acknowledgement}

This work is supported by the European Community through the LANCER Project (FP6-IST 033574).

\section{References}

[1] A. Polman, J. Appl. Phys. 82 (1997) 1.

[2] F. Priolo, G. Franzò, S. Coffa, A. Carnera, Phys. Rev. B 57 (1998) 4443.

[3] W. Miniscalco, in: M. Digonnet (Ed.), Rare-Earth-Doped Fiber Lasers and Amplifiers, Dekker, New York, 2001, p. 62.

[4] A.J. Kenyon, P.F. Trwoga, M. Federighi, C.W. Pitt, J. Phys.: Condens. Matter 6 (1994) L319.

[5] M. Fujii, M. Yoshida, Y. Kansawa, S. Hayaski, K. Yamamoto, Appl. Phys. Lett. 71 (1997) 1198

[6] J.H. Shin, K. Kim, S. Seo, C. Lee, Appl. Phys. Lett. 72 (1998) 1092.

[7] G. Franzò, V. Vinciguerra, F. Priolo, Appl. Phys. A: Mater. Sci. Process. 69 (1999) 3.
[8] M. Wodjak, M. Klik, M. Forcales, O.B. Gusev, T. Gregorkiewicz, L. Pacifici, G. Franzò, F. Priolo, F. Iacona, Phys. Rev. B 69 (2004) 233315.

[9] F. Gourbilleau, C. Dufour, M. Levalois, J. Vicens, R. Rizk, C. Sada, F. Enrichi, G. Battaglin, J. Appl. Phys. 94 (2003) 3869.

[10] K. Watanabe, M. Fujii, S. Hayashi, J. Appl. Phys. 90 (2001) 4761.

[11] F. Priolo, G. Franzò, D. Pacifici, V. Vinciguerra, F. Iacona, A. Irrera, J. Appl. Phys. 89 (2001) 264.

[12] D. Kovalev, J. Diener, H. Heckler, G. Polisski, N. Künzner, F. Koch, Phys. Rev. B 61 (2000) 4485.

[13] G. Franzò, S. Boninelli, D. Pacifici, F. Priolo, F. Iacona, C. Bongiorno, Appl. Phys. Lett. 82 (2003) 3871.

[14] F. Gourbilleau, L. Levalois, C. Dufour, J. Vicens, R. Rizk, J. Appl. Phys. 95 (2004) 3717.

[15] J.H. Jhe, J.H. Shin, K.J. Kim, D.W. Moon, Appl. Phys. Lett. 82 (2003) 4489.

[16] F. Gourbilleau, C. Dufour, R. Madelon, R. Rizk, J. Lumin. 126 (2007) 581.

[17] B. Garrido, C. Garcia, P. Pellegrino, D. Navarro-Urrios, N. Daldosso, L. Pavesi, F. Gourbileau, R. Rizk, Appl. Phys. Lett. 89 (2006) 163103.

[18] B. Garrido, C. García, S.-Y. Seo, P. Pellegrino, D. Navarro-Urrios, N. Daldosso, L. Pavesi, F. Gourbilleau, R. Rizk, Phys. Rev. B 76 (2007) 245308.

[19] C. Ternon, F. Gourbilleau, X. Portier, P. Voivenel, C. Dufour, Thin Solid Films 419 (2002) 5.

[20] N. Tomozeiu, Appl. Surf. Sci. 25 (2006) 376

[21] F. Gourbilleau, et al., Physica E, this issue. 